\title{
SARS-CoV-2: big seroprevalence data from Pakistan-is herd immunity at hand?
}

\author{
Mohsina Haq ${ }^{1}$. Asif Rehman ${ }^{1}$ (D) Junaid Ahmad ${ }^{2}$. Usman Zafar ${ }^{3}$. Sufyan Ahmed ${ }^{4} \cdot$ Mumtaz Ali Khan $^{5}$. \\ Asif Naveed ${ }^{6}$. Hala Rajab ${ }^{1}$. Fawad Muhammad ${ }^{1}$. Wasifa Naushad ${ }^{1}$ Muhammad Aman ${ }^{1} \cdot$ Hafeez Ur Rehman ${ }^{1}$. \\ Sajjad Ahmad ${ }^{1}$. Saeed Anwar ${ }^{1} \cdot$ Najib UI Haq $^{1}$
}

Received: 21 January 2021 / Accepted: 14 May 2021 / Published online: 25 May 2021

○) Springer-Verlag GmbH Germany, part of Springer Nature 2021

\begin{abstract}
Purpose Seroprevalence surveys from different countries have reported SARS CoV-2 antibodies below 20\% even in the most adversely affected areas and herd immunity cannot be predicted till more than half of the population gets the disease. The purpose of this survey was to estimate the magnitude of community-based spread of the infection, associated immunity, and the future prospects and proximity to a 'herd community'.

Methods The study was undertaken as a cluster randomized, cross-sectional countrywide survey. This largest communitybased seroprevalence data of SARS-CoV-2 were collected between 15th and 31st July, 2020 from seven randomly selected cities belonging to the three most populous provinces of Pakistan. The FDA approved kit of ROCHE was used for detection of SARS-CoV-2 antibodies.

Results Serum samples of 15,390 participants were tested for SARS CoV-2 antibodies with an overall seroprevalence of 42.4\%. The seroprevalence ranged from $31.1 \%$ to $48.1 \%$ in different cities with the highest in Punjab province (44.5\%). In univariable analysis, the odds of seropositivity was higher in men compared to women (OR: 1.10, 95\% CI: 1.01-1.19, $P<0.05)$. In multivariable analysis, the risk of being seropositive was lower (OR $0.72,95 \%$ CI: $0.60-0.87, P<0.01)$ in younger group $(\leq 20$ years) than in those aged above 60 years.

Conclusion The study concluded that despite a reasonable seroprevalence, the country is yet to reach the base minimum of estimations for herd immunity. The durability of immunity though debated at the moment, has shown an evidenced informed shift towards longer side.
\end{abstract}

Keywords Seroprevalence $\cdot$ Sars $\cdot \mathrm{CoV}-2 \cdot$ Antibody $\cdot$ Herd $\cdot$ Immunity

\author{
Abbreviations \\ SARS CoV-2 Severe acute respiratory syndrome corona- \\ virus 2 \\ COVID-19 Coronavirus infectious disease \\ KPK Khyber Pakhtunkhwa \\ Asif Rehman \\ asifrehman173@gmail.com \\ 1 Peshawar Medical College, Riphah International University, \\ Warsak Road, Peshawar, Pakistan \\ 2 Prime Institute of Public Health, Peshawar Medical College, \\ Warsak Road, Peshawar, Pakistan \\ 3 Islamabad Medical and Dental College, Islamabad, Pakistan \\ 4 Al-Khidmat Health Foundation, Lahore, Pakistan \\ 5 National Institute of Health, Islamabad, Pakistan \\ 6 University of Health Sciences, Lahore, Pakistan
}

$\begin{array}{ll}\text { RT-PCR } & \begin{array}{l}\text { Reverse transcription polymerase chain } \\ \text { reaction }\end{array} \\ \text { UCs } & \text { Union councils } \\ \text { FDA } & \text { Food and drug administration } \\ \text { VOC } & \text { Variants of concern } \\ \text { LMICs } & \text { Low to middle income countries }\end{array}$

\section{Introduction}

Novel Coronavirus related disease (COVID-19) started from China in December 2019, while Pakistan declared its two positive cases on 26th Feb 2020 [1]. Word Health Organization declared SARS-CoV-2 a global pandemic on March 11, 2020 and since then the cases are on the rise world-wide, resulting in unprecedented effects on human life [2]. The WHO COVID-19 statistics of confirmed 
cases were 81,533,368 till December 31, 2020 including $1,799,911$ deaths world-wide [3]. Like many other countries Pakistan witnessed its highest number of new cases and mortalities during the month of June 2020 followed by a steep fall $[4,5]$. The measures taken by the government of Pakistan and the resultant decline in cases has been much praised by the world $[6,7]$ but the reasons cannot be fully explained (due to lack of supporting evidence/ data) [5]. There has been a resurge of COVID-19 with start of winter and the number of confirmed cases rose by 110,530 including 2060 deaths from end of October to mid-December 2020 [8]. The widespread infection has affected all provinces of Pakistan with 230,718 cases in Sindh, 62,377 in Khyber Pakhtunkhwa, 147,292 cases in Punjab and 39,624 cases in capital territory Islamabad [8]. Reverse Transcription Polymerase Chain Reaction (RT-PCR) is the gold standard to confirm SARS-CoV-2 infection. However, it may miss several pre-symptomatic and asymptomatic infections during latency and does not provide information about immunity against the disease which could help illustrate the state of herd immunity in community $[9,10]$. Studies have reported cases of reinfection with SARS CoV-2 [11-13] but some other studies have concluded that a positive PCR retest could be due to several other reason like infection by mutated SARS Cov- 2 and technical error with specimen collection $[14,15]$.

Seroprevalence surveys also provide estimates of the population still vulnerable to the infection [16]. A true community-based seroprevalence survey is still lacking in Pakistan while most of the studies conducted are hospital based and with a varying level of infection (11-40\%), given the fact that several of them were based on recall [17-19].

Herd immunity is still not foreseeable in many countries of the world as seroprevalence population surveys reveal antibodies as low as $10-15 \%$ [20] and herd immunity cannot be predicted till more than half of the population gets the disease [21]. Herd immunity against a contagious disease like COVID-19 could be achieved when $70-90 \%$ of the population becomes immune due to mass scale vaccination or exposure to infection [22]. The second surge of COVID19 has already been established in many countries including Pakistan [23, 24]. This makes it very important to understand the immune response in different populations as it has important public health and policy implications [25, 26]. However, it is still unclear whether herd immunity through vaccine or previous infection may be achievable.

This community-based seroprevalence study was conducted in the three major provinces of Pakistan having more than $90 \%$ of country population. The purpose was to have a better estimation of the spread of infection at the community level, the associated immunity pattern to COVID-19 and the prospects of proximity to a herd immunity in future.

\section{Methodology}

This study was undertaken as a cluster randomized, crosssectional countrywide survey. Seven out of ninety-nine cities were randomly selected as a study clusters. In each cluster, participants were recruited via mobile camping from randomly selected Union Councils (an administrative unit within district with a population size of 25,000-35,000). The clusters included Peshawar, Karachi, Lahore, Multan, Mansehra, Rawalpindi, Multan and Hyderabad from three major provinces (Khyber Pakhtunkhwa, Sindh and Punjab). The study was conducted from 15th to 31 st July 2020 following an approval from Institutional Review Board (IRB) of Prime Foundation, Pakistan (IRB approval no. Prime/IRB/2020-248). After taking an informed consent, $5 \mathrm{~mL}$ of peripheral venous blood was collected in lithium heparin container. Basic demographic data of the consenting subjected was recorded on a structured tool.

\section{Storing, processing and diagnostic labeling of the phlebotomy samples}

The samples were transported to laboratories in specialized containers ensuring temperature control. Serum was separated, centrifuged at $2500 \mathrm{rpm}$, stored in labeled cups and $20 \mu \mathrm{L}$ used for analysis. The samples were analyzed using Elecsys ${ }^{\circledR}$ (Roche, Basel, Switzerland) Anti-SARSCoV-2 immunoassay. The assay uses a recombinant protein representing the nucleocapsid $(\mathrm{N})$ antigen for the determination of antibodies against SARS-CoV-2. It is an immunoassay for the in vitro qualitative detection of antibodies that includes IgG to SARS-CoV-2 in human serum and plasma [27]. The FDA approved kit of ROCHE used for the detection of immunoglobulins against SARSCoV-2 has high specificity (100\%) and sensitivity of more than $98.8 \%$, according to the manufacturer [28]. However, the Public Health England estimates its specificity to be $100 \%$ but sensitivity of $87 \%$ [29]. The cut off for significant antibodies level was taken as $1 \mathrm{AU} / \mathrm{mL}$ as per manufacturers instruction.

\section{Statistical analysis}

The data was entered and analyzed in SPSS version 24.0. The means, median, standard deviations were calculated for the continuous variables, while frequencies, counts and percentages were calculated for the categorical variables. Confidence interval for the proportions were calculated using Binomial Exact methods. Chi-square test was used 
to compare between categorical variables like sex, age group and location. The logistic regression analysis was run to predict the odds of seropositivity among different age groups. The threshold for statistical significance was established at a $P$ value $\leq 0.05$.

\section{Results}

A total number of 15,390 serum samples (one sample per individual) were tested for SARS CoV-2 antibodies from three major provinces of Pakistan in seven different locations, as specified in the methods above. Table 1 shows the seroprevalence estimates by sex, age groups and different locations. Majority of the participants belonged to Punjab province $(n=8872,57.6 \%)$ followed by Khyber Pakhtunkhwa $(n=4797,31.2 \%)$ and Sindh Province $(n=1721$, $11.2 \%)$.

Of the total, $12,280(79.8 \%)$ were male participants and $3110(20.2 \%)$ were female with a mean age of 35.21 years $(\mathrm{SD} \pm 13.29)$. The age group of $21-40$ years comprised the majority number of people $(n=9348,60.7 \%)$ while the age group of above 60 years comprising the lowest number of participants $(n=652,4.2 \%)$.

During the study period, of the total sample $(n=15,390)$, 6518 tested found positive for SARS COV-2 antibodies with an overall seroprevalence of $42.4 \%$ (Binomial Exact 95\% CI: 41.5-43.14). In different age groups, older age group of above 60 years had the highest seropositivity (44.6\%, 95\% CI: 40.7-48.5) while the lowest seropositivity were estimated in younger age group of $\leq 20(36.7 \%$, 95\% CI: 34.2-39.1) (Table 1). The seroprevalence was highest in Punjab province (44.5\%) (Binomial Exact 95\% CI: 43.5-45.6) followed by Khyber Pakhtunkhwa (42.2\%) (Binomial Exact 95\% CI: 41.2-44.0) and Sindh province (31.8\%) (Binomial Exact 95\% CI: 29.6-34.1) with statistical significant association $(P<0.01)$ when chi-square test was applied. The city-wise seroprevalence was also calculated that ranged from 31.1\% (Binomial Exact 95\% CI: 28.8-33.3) in Mansehra city to $48.1 \%$ (Binomial Exact $95 \%$ CI: 46.3-49.8) in Peshawar city (Fig. 1). For the remaining five locations, the seroprevalence estimates fell within this range (31.1-48.1\%).

In univariable analysis, the odds of seropositivity was higher in men compared to women (OR: 1.10, 95\% CI: $1.01-1.19, P<0.05)$ but was not statistically significant in multivariable analysis $(P>0.05)$ (Table 2). The odds of seropositivity in multivariable analysis were low in younger age ( $\leq 20$ years) with an OR: $0 \cdot 72,95 \%$ CI: $0.60-0.87$ when compared with the age group of above 60 years and had a highly statistically significant $P$ value of $<0.01$. Similarly, the age groups of $20-40$ and $41-60$ years also had a lower risk of being seropositive (OR: 0.91, 95\% CI: 0.77-1.07) and (OR: $0.98,95 \%$ CI: $0.83-1.16$ ) respectively to the age group of above 60 years and was found to be numerically higher $(P=0.25, P=0.88)$ (Table 2$)$.

\section{Discussion}

During the current pandemic, serological testing appears to be a useful strategy to determine the human-to-human transmission of COVID-19. The utilization of serological tests in the asymptomatic population or those showing mild
Table 1 Demographic characteristics and seroprevalence

\begin{tabular}{lcllll}
\hline & $\begin{array}{l}\text { Number of } \\
\text { participants } \\
n\end{array}$ & $\begin{array}{l}\text { Seropositive } \\
n(\%)\end{array}$ & $\begin{array}{l}\text { Seronegative } \\
n(\%)\end{array}$ & $\begin{array}{l}\text { Seroprevalence }(95 \% \\
\text { CI) binomial exact }\end{array}$ & $P$ value \\
\hline $\begin{array}{l}\text { Overall } \\
\text { Sex }\end{array}$ & 15,390 & $6518(42.4 \%)$ & $8872(57.6 \%)$ & $42.4 \%(41.5-43.14)^{\mathrm{a}}$ & \\
Male & 12,280 & $5259(42.8 \%)$ & $7021(57 \cdot 2 \%)$ & $42.8 \%(41.9-43 \cdot 7)^{\mathrm{a}}$ & $<0.05^{\mathrm{b}}$ \\
Female & 3110 & $1259(40.5 \%)$ & $1851(59.9 \%)$ & $40.5 \%(38.7-42 \cdot 2)^{\mathrm{a}}$ & \\
Age groups & & & & & \\
$\leq 20$ & 1549 & $568(36.7 \%)$ & $981(63.3 \%)$ & $36.7 \%(34.2-39.1)^{\mathrm{a}}$ & $<0.01^{\mathrm{b}}$ \\
$21-40$ & 9348 & $3957(42.3 \%)$ & $5391(57.7 \%)$ & $42.3 \%(41.3-43.3)^{\mathrm{a}}$ & \\
$41-60$ & 3841 & $1702(44.3 \%)$ & $2139(55.7 \%)$ & $44.3 \%(42.7-45.9)^{\mathrm{a}}$ & \\
Above 60 & 652 & $291(44.6 \%)$ & $361(55.4 \%)$ & $44.6 \%(40.7-48.5)^{\mathrm{a}}$ & \\
Province & & & & & \\
Khyber Pakhtunkhwa & 4797 & $2025(42.2 \%)$ & $2772(57.8 \%)$ & $42.2 \%(41.2-44.0)^{\mathrm{a}}$ & $<0.01^{\mathrm{b}}$ \\
Sindh & 1721 & $548(31.8 \%)$ & $1173(68.2 \%)$ & $31.8 \%(29.6-34.1)^{\mathrm{a}}$ & \\
Punjab & 8872 & $3954(44.5 \%)$ & $4927(55.5 \%)$ & $44.5 \%(43.5-45.6)^{\mathrm{a}}$ & \\
\hline
\end{tabular}

${ }^{a}$ Unweighted seroprevalence of SARS CoV-2 with 95\% CI calculated using Binomial Exact method

${ }^{\mathrm{b}} \mathrm{Chi}$ square test with significance level of $<0.05$ 
Fig. 1 Seroprevalence of SARSCoV-2 in different cities of Pakistan

\section{Seroprevalence by Cities}

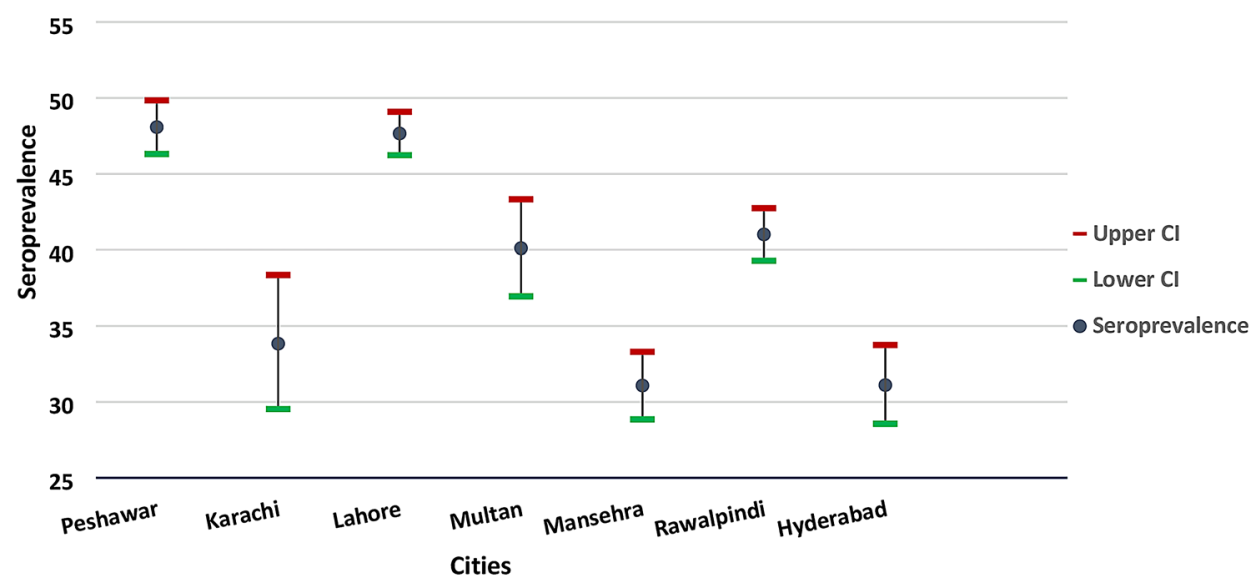

Table 2 Univariable and multivariable analysis of sex and age group with seropositivity

\begin{tabular}{|c|c|c|c|c|c|c|}
\hline \multirow[t]{2}{*}{ Relative variable } & \multicolumn{3}{|c|}{ Univariable analysis } & \multicolumn{3}{|c|}{ Multivariable analysis } \\
\hline & OR & $95 \% \mathrm{CI}$ & $P$ value & OR & $95 \%$ CI & $P$ value \\
\hline \multicolumn{7}{|l|}{ Sex } \\
\hline \multicolumn{7}{|l|}{ Female (Ref) } \\
\hline Male & 1.10 & $1.01-1.19$ & $0.01 *$ & 1.07 & $0.99-1.16$ & 0.07 \\
\hline \multicolumn{7}{|l|}{ Age group } \\
\hline \multicolumn{7}{|c|}{ Above 60 years (Ref) } \\
\hline$\leq 20$ years & 0.72 & $0.60-0.86$ & $0.001^{*}$ & 0.72 & $0.60-0.87$ & $0.001^{*}$ \\
\hline $21-40$ years & 0.91 & $0.78-1.07$ & 0.24 & 0.91 & $0.77-1.07$ & 0.25 \\
\hline $41-60$ years & 0.99 & $0.84-1.17$ & 0.87 & 0.98 & $0.83-1.16$ & 0.88 \\
\hline
\end{tabular}

Adjusted odd ratio with 95\% Confidence Interval and their $P$ value

* Refers to $P$ value with statistically significant association symptoms is crucial, as they rarely opt for PCR testing [30] masking the population's actual rate of infection. Different studies conducted in different parts of the world have indicated that many people who tested positive for SARS-CoV-2 showed no symptoms [31-33].

This study conducted serological tests for COVID-19 of the population from three provinces of Pakistan. The seropositivity increased with increase in age in our study. An up-to-date review by Lai and colleagues reported this to be the case in some other studies also but was not a universal finding, however in all the studies [34]. Furthermore, neither they nor Anand et al. in a big data review in USA found any significant difference for seropositivity among the males and females [34, 35]. Our study on multivariable analysis also did not find any significant difference for seropositivity among the sexes. However, the study found out an overall seroprevalence of $42.4 \%$. Knowing that when majority of a population is immune to an infectious disease, it provides an indirect protection, i.e., herd immunity to those who are not immune to the disease. Given that effective vaccination for
COVID-19 has host of affordability and supply-chain issues especially for developing countries coupled with the fact that the influenza viruses are believed to be rapidly mutating, the natural course of infection remains the major possibility for acquiring herd immunity [36].

Questions have been raised about the time duration of the immunity against COVID-19. A recent study published in Science Journal reported that immunological memory to SARS-CoV-2 can last longer than six months and revealed further that spike-IgG was relatively stable over six-plus months, and spike-specific memory B cells were more abundant at six months than at one month [37].

The news regarding the emergence of a variant of concern (VOC) in UK of Brazilian origin might pose a challenging scenario in terms of tracking and controlling the spread of the VOCs and understanding their effects on the pandemic especially in the low to middle income countries (LMICs). This as well as the short-lived immunity associated with flu like pandemics doesn't preclude reinfection and problems in achieving a herd immunity [38]. 


\section{Conclusion}

The overall seroprevalence of SARS CoV-2 antibodies in Pakistan was reasonably high in this study (as of June 2020) but still short of the base minimum for herd immunity. The seroprevalence varied in the different cities of Pakistan and by age and gender, also. The immunity though dependent on a number of the agent, host, and environment factors, may not be very short-lived ( 3 months or so as was believed earlier), and with passing time, evidence is mounting that points towards longevity of the immunity much beyond that.

\section{Limitation}

A limitation to keep in mind might be the selection bias that may have occurred due to voluntary participation from randomly selected UCs.

Supplementary Information The online version contains supplementary material available at https://doi.org/10.1007/s15010-021-01629-2.

Acknowledgements The authors would like to thank all study participants, the field and the lab staff involved in serum collection and analysis for this study.

Funding Funding for this study was provided by Al-Khidmat Health Foundation while SARS CoV-2 antibody kits were donated by ROCHE.

Availability of data and material Study data are available from the corresponding author on reasonable request.

\section{Declarations}

Conflict of interest The authors of this study declare that they have no known competing financial interests or personal relationships that could have appeared to influence the work reported in this study.

\section{References}

1. Noreen N, Dil S, Niazi S, Naveed I, Khan N, Khan F, et al. COVID 19 pandemic \& Pakistan; limitations and gaps. Glob Biosecurity [Internet]. 2020 May 21 [cited 2020 Nov 15]; 1(4). Available from http://jglobalbiosecurity.com/articles/https://doi.org/10.31646/ gbio.63/

2. Mahase E. Covid-19: WHO declares pandemic because of "alarming levels" of spread, severity, and inaction. BMJ. 2020;m1036.

3. WHO Coronavirus Disease (COVID-19) Dashboard [Internet]. Covid19.who.int. 2020 [cited 13 December 2020]. Available from: https://covid19. who.int/?ftag=MSF0951a18

4. Pakistan Coronavirus: 356,904 Cases and 7,141 Deaths-Worldometer [Internet]. [cited 2020 Nov 15]. Available from: https:// www.worldometers.info/coronavirus/country/pakistan/

5. Unexplained decline in COVID-19 cases' puzzles health experts [Internet]. Thenews.com.pk.2020 [cited 18 December 2020]. Available from: https://www.thenews.com.pk/print/687387-unexp lained-decline-in-covid-19-cases-in-pakistan-puzzles-healthexperts-and-policymakers
6. Former WB chief economist praises Pakistan's handling of coronavirus [Internet]. [cited 2020 Nov 15]. Available from: https:// www.thenews.com.pk/print/731496-former-wb-chief-economistpraises-pakistan-s-handling-of-coronavirus

7. Dawn.com A. WHO chief lauds Pakistan for suppressing Covid19 while keeping economy afloat [Internet]. DAWN.COM. 2020 [cited 2020 Nov 15]. Available from: https://www.dawn.com/ news/1582311

8. COVID-19 Health Advisory Platform by Ministry of National Health Services Regulations and Coordination [Internet]. Covid. gov.pk. 2020 [cited 18 December 2020]. Available from: https:// covid.gov.pk/.

9. Gao Z, Xu Y, Sun C, Wang X, Guo Y, Qiu S, et al. A systematic review of asymptomatic infections with COVID-19. J Microbiol Immunol Infect. 2021;54:12-6.

10. Moghadas S, Fitzpatrick M, Sah P, Pandey A, Shoukat A, Singer $\mathrm{BH}$, et al. The implications of silent transmission for the control of COVID-19 outbreaks. Proc Natl Acad Sci. 2020;117:17513-5.

11. Ye G, Pan Z, Pan Y, Deng Q, Chen L, Li J, et al. Clinical characteristics of severe acute respiratory syndrome coronavirus 2 reactivation. J Infect. 2020;80:e14-7.

12. Ravioli S, Ochsner H, Lindner G. Reactivation of COVID-19 pneumonia: a report of two cases. J Infect. 2020;81:e72-3.

13. Loconsole D, Passerini F, Palmieri V, Centrone F, Sallustio A, Pugliese S, et al. Recurrence of COVID-19 after recovery: a case report from Italy. Infection. 2020;48:965-7.

14. SeyedAlinaghi S, Oliaei S, Kianzad S, Afsahi A, MohsseniPour M, Barzegary A, et al. Reinfection risk of novel coronavirus (CoVID-19): a systematic review of current evidence. World J Virol. 2020;9:79-90.

15. Colson P, Finaud M, Levy N, Lagier J, Raoult D. Evidence of SARS-CoV-2 re-infection with a different genotype. J Infect. 2021;82:84-123.

16. Khan S, Qurieshi M, Haq I, Majid S, Bhat A, Nabi S, et al. Seroprevalence of SARS-CoV-2 specific IgG antibodies in District Srinagar, northern India - a cross-sectional study. PLoS ONE. 2020;15:e0239303.

17. Younas A, Waheed S, Khawaja S, Imam M, Borhany M, Shamsi T. Seroprevalence of SARS-CoV-2 antibodies among healthy blood donors in Karachi, Pakistan. Transf Apheresis Sci. 2020;59:102923.

18. Javed W, Baqar JB, Abidi SHB, Farooq W. Sero-prevalence findings from metropoles in Pakistan: implications for assessing COVID-19 prevalence and case-fatality within a dense, urban working population. Arch Epidemiol. 2020;4:143.

19. Chughtai OR, Batool H, Khan MD, Chughtai AS. Frequency of COVID-19 IgG antibodies among special police Squad Lahore, Pakistan. J Coll Physician Surg Pak. 2020;30:735-9.

20. Byambasuren O, Dobler C, Bell K, Rojas DP, Clark J, McLaws $\mathrm{M}-\mathrm{L}$, et al. Comparison of seroprevalence of SARS-CoV-2 infections with cumulative and imputed COVID-19 cases: systematic review. PLoS ONE. 2021;16:e0248946.

21. Fontanet A, Cauchemez S. COVID-19 herd immunity: where are we? Nat Rev Immunol. 2020;20:583-4.

22. Rogers L, Health J. What is herd immunity and how can we achieve it with COVID-19? [Internet]. Johns Hopkins Bloomberg School of Public Health. 2020 [cited 18 December 2020]. Available from: https://www.jhsph.edu/covid-19/articles/achie ving-herd-immunity-with-covid19.html

23. Looi M. Covid-19: is a second wave hitting Europe?. BMJ. 2020:m4113.

24. Second wave of Covid-19 in Pakistan; are more episodes down the road? [Internet]. The BMJ. 2020 [cited 18 December 2020]. Available from: https://www.bmj.com/content/371/bmj.m4113/ rr-0 
25. Nature. 2020. Why decoding the immune response to COVID matters for vaccines. Nature. Accessed: 10 Aug 2020. Available from: https://www.nature.com/articles/d41586-020-02943-9

26. Nature. 2020. Why decoding the immune response to COVID matters for vaccines. Nature. Accessed: 14 June 2020. Available from: https://media.nature.com/original/magazine-assets/d41586020-02943-9/d41586-020-02943-9

27. Elecsys ${ }^{\circledR}$ Anti-SARS-CoV-2 [Internet]. Diagnostics. 2021 [cited 01 April 2021]. Available from: https://diagnostics.roche.com/ global/en/products/params/elecsys-anti-sars-cov-2.html

28. Roche's COVID-19 antibody test receives FDA Emergency Use Authorization and is available in markets accepting the CE mark. Accessed 14 Sep, 2020.Available from: http://www.roche.com/ media/releases/med-cor-2020-05-03.html

29. Baraniuk C. Covid-19 antibody tests: a briefing. BMJ. 2020;369:m2284.

30. Infantino M, Damiani A, Li Gobbi F, Grossi V, Lari B, Macchia $\mathrm{D}$, et al. An overview on advantages and limitations of serological assays for saRs-coV-2 infectious disease. Italian J Lab Med. 2020;16:7-17.

31. Sutton D, Fuchs K, D'Alton M, Goffman D. Universal screening for SARS-CoV-2 in women admitted for delivery. N Engl J Med. 2020;382:2163-4
32. Li R, Pei S, Chen B, Song Y, Zhang T, Yang W, et al. Substantial undocumented infection facilitates the rapid dissemination of novel coronavirus (SARS-CoV-2). Science. 2020;368:489-93.

33. Gudbjartsson DF, Helgason A, Jonsson H, Magnusson OT, Melsted P, Norddahl GL, et al. Spread of SARS-CoV-2 in the Icelandic population. N Engl J Med. 2020;382:2302-15.

34. Lai C, Wang J, Hsueh P. Population-based seroprevalence surveys of anti-SARS-CoV-2 antibody: an up-to-date review. Int J Infect Dis. 2020;101:314-22.

35. Anand S, Montez-Rath M, Han J, Bozeman J, Kerschmann R, Beyer P, et al. Prevalence of SARS-CoV-2 antibodies in a large nationwide sample of patients on dialysis in the USA: a crosssectional study. Lancet. 2020;396:1335-44.

36. Mills MC, Salisbury D. The challenges of distributing COVID-19 vaccinations. E Clin Med. 2020;100674.

37. Dan JM, Mateus J, Kato Y, et al. Immunological memory to SARS-CoV-2 assessed for up to 8 months after infection. Science. 2021;371:eabf4069.

38. Covid-19: Brazil 'variant of concern' detected in UK [Internet]. BBC News. 2021 [cited 01 April 2021]. Available from: https:// www.bbc.com/news/uk-56233038 